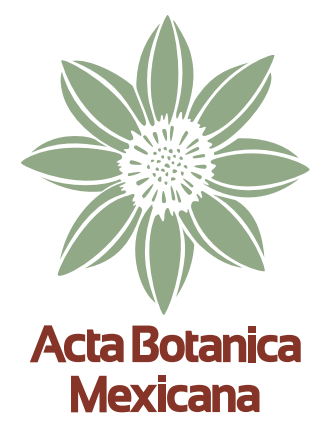

\title{
Eloy Solano Camacho (1955-2021)
}

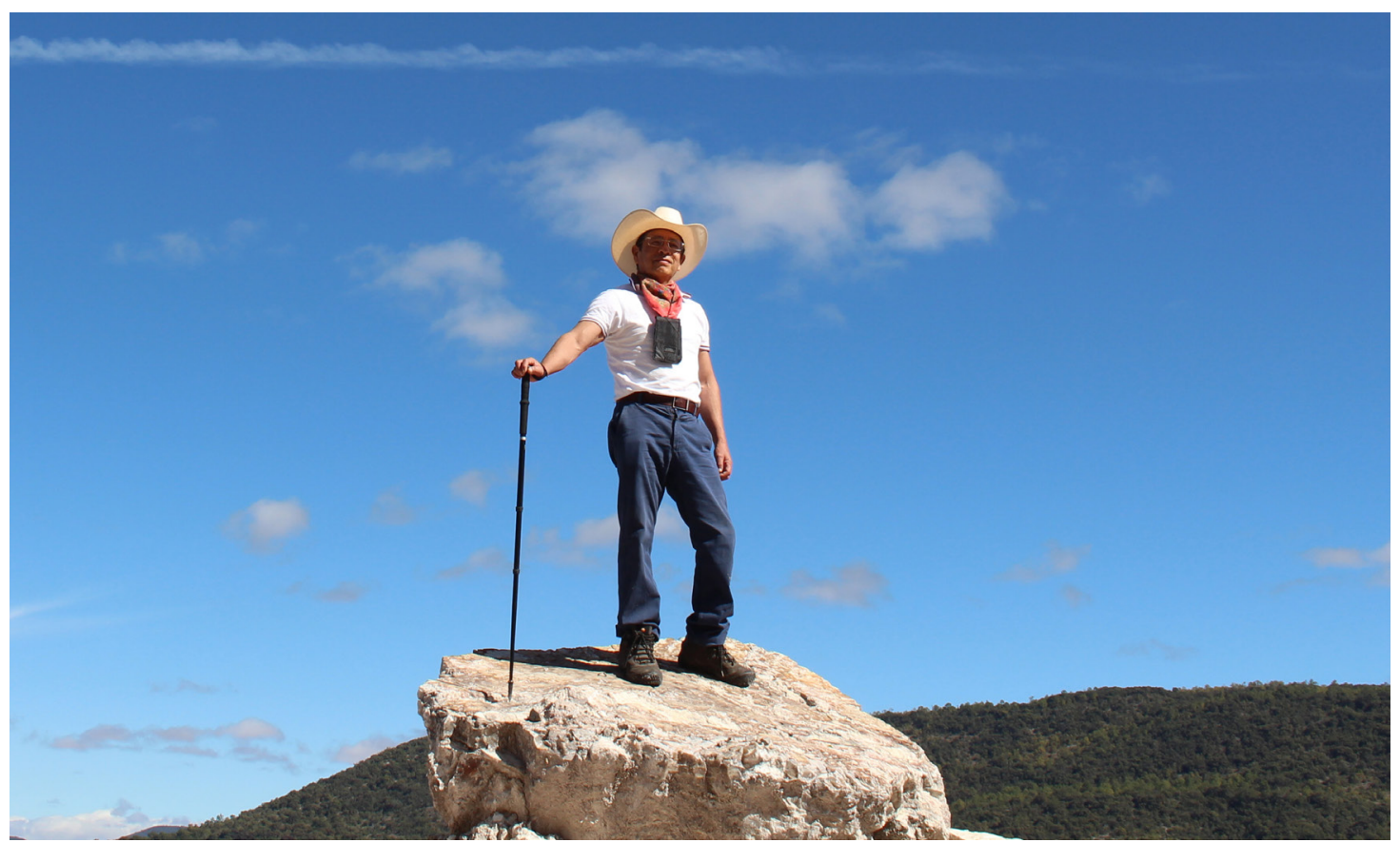

Eloy Solano Camacho en Oaxaca, México (Foto de Ramiro Ríos Gómez).

María Magdalena Ayala-Hernández,2(1)

\section{Maestro, colega, amigo y mentor \\ Maestro, colega, amigoy mentor}

Incansable y apasionado estudioso de la Flora de México, principalmente del estado de Oaxaca de donde era orgullosamente originario y donde también concluyó sus días. Su dedicación y compromiso quedaron patentes en dos fascículos de la Flora del Bajío y de Regiones Adyacentes, así como en cuatro de la Flora del Valle de Tehuacán-
${ }^{1}$ Universidad Nacional Autónoma de México, Facultad de Estudios Superiores Zaragoza, Unidad de Investigación en Sistemática Vegetal y Suelo, Batalla 5 de mayo s/n, Ejército de Oriente, 09230 Ciudad de México, México.

${ }^{2}$ Autor para la correspondencia: airamagay@yahoo. com.mx
Cuicatlán, en la descripción de 14 especies nuevas, 13 de ellas monocotiledóneas, la publicación de 42 artículos de investigación, seis capítulos de libro y otros productos científicos. Colaboró en ocho proyectos de investigación, dictó 92 ponencias en congresos nacionales e internacionales, y 44 conferencias, entre muchos otros logros.
Recibido: 2 de febrero de 2022

Revisado: 2 de febrero de 2022.

Aceptado por Marie-Stéphanie Samain: 8 de febrero de 2022.

Publicado Primero en línea: 10 de febrero de 2022

Publicado: Acta Botanica Mexicana 129(2022).
Citar como: Ayala-Hernández, M. M. 2022. Obituario Eloy Solano Camacho. Acta Botanica Mexicana 129: e2021. DOI: https://doi.org/10.21829/ abm129.2022.2021 
Por su trayectoria y experiencia fue invitado para evaluar distintos proyectos sobre la generación de nuevos conocimientos en el área de la Botánica. Sus estudios han sido citados en 54 artículos especializados e indizados a nivel internacional. Durante 39 años trabajó como profesor de la Facultad de Estudios Superiores, unidad Zaragoza (FES Zaragoza) de la Universidad Nacional Autónoma de México (UNAM) e impartió 40 cursos curriculares; 29 más los dictó fuera de la UNAM. También dirigió más de 45 estudios que versaron sobre diferentes áreas de investigación relacionadas con las plantas y fue curador del Herbario FEZA en diferentes períodos. En años más recientes formó parte del Sistema Nacional de Investigadores (SNI).

Aquellos que interactuamos con él nos percatamos de la disciplina con que realizaba cada una de sus actividades: la de maestro, director de tesis, responsable de proyectos y curador del herbario FEZA. Siempre exigente con sus alumnos y colaboradores, como lo era consigo mismo. Su forma de ser le impedía postergar el trabajo y, urgente o no, nunca paraba de trabajar, por lo que sacrificaba vacaciones y fechas festivas para terminar proyectos, artículos, tesis $\mathrm{u}$ otros pendientes. Cómo no recordar las salidas al campo con sus peculiares anécdotas, las clases puntuales de las 7:00 y las revisiones interminables de los manuscritos. De estas últimas cuidaba todos los detalles, desde los signos de puntuación hasta los aspectos de fondo de los manuscritos completos; su afición para escribir era bien conocida.

Lamentamos su repentina partida, pero continuaremos con su legado. No será un camino fácil; sin embargo, él nos enseñó que es posible y no concebimos una mejor forma de brindarle homenaje que mediante el trabajo arduo. Sus estudiantes lo recordaremos de muchas maneras, porque sin duda dejó una huella en nosotros, en las actividades de campo y laboratorio, en cada proyecto, en las especies que describió e incluso en las malas palabras de sus regaños; ahora entendemos su empeño para que aprendiéramos. Extrañaremos también su personalidad apabullante, socarrona e incluso demasiado directa. Nuestro más profundo agradecimiento Doctor Eloy Solano, por todas sus enseñanzas, por el tiempo dedicado, por su ejemplo de trabajo y por su disciplina. Hasta donde esté, muchas gracias. 